\title{
Black Pod Syndrome of Lupinus angustifolius Is Caused by Late Infection with Bean yellow mosaic virus
}

M. A. Kehoe, B. J. Buirchell, B. A. Coutts, and R. A. C. Jones, School of Plant Biology and Institute of Agriculture, Faculty of Science, University of Western Australia, Crawley, WA 6009, Australia; and Crop Protection and Lupin Breeding Branches, Department of Agriculture and Food Western Australia, Bentley Delivery Centre, Perth, WA 6983, Australia

\begin{abstract}
Kehoe, M. A., Buirchell, B. J., Coutts, B. A., and Jones, R. A. C. 2014. Black pod syndrome of Lupinus angustifolius is caused by late infection with Bean yellow mosaic virus. Plant Dis. 98:739-745.

Black pod syndrome (BPS) causes devastating losses in Lupinus angustifolius (narrow-leafed lupin) crops in Australia, and infection with Bean yellow mosaic virus (BYMV) was suggested as a possible cause. In 2011, an end-of-growing-season survey in which L. angustifolius plants with BPS were collected from six locations in southwestern Australia was done. Tissue samples from different positions on each of these symptomatic plants were tested for BYMV and generic potyvirus by enzyme-linked immunosorbent assay and reverse-transcription polymerase chain reaction (RT-PCR). Detection was most reliable when RT-PCR with generic potyvirus primers was used on tissue taken from the main stem of the plant just below the black pods. Partial coat protein nucleotide sequences from eight isolates from BPSsymptomatic L. angustifolius plants all belonged to the BYMV general

phylogenetic group. An initial glasshouse experiment revealed that mechanical inoculation of $L$. angustifolius plants with BYMV after pods had formed caused pods to turn black. This did not occur when the plants were inoculated before this growth stage (at first flowering) because BYMV infection caused plant death. A subsequent experiment in which plants were inoculated at eight different growth stages confirmed that BPS was only induced when L. angustifolius plants were inoculated after first flowering, when pods had formed. Thus, BYMV was isolated from symptomatic $L$. angustifolius survey samples, inoculated to and maintained in culture hosts, inoculated to healthy $L$. angustifolius test plants inducing BPS, and then successfully reisolated from them. As such, Koch's postulates were fulfilled for the hypothesis that late infection with BYMV causes BPS in L. angustifolius plants.
\end{abstract}

The genus Lupinus (lupin) contains several annual species grown as cool-season grain legumes. These species are planted as rain-fed summer crops in regions of the world with cool temperate climates, as rain-fed winter crops in regions with Mediterraneantype climates, and as rain-fed wet season or irrigated crops at high altitude in tropical regions (11). Australia is currently the largest lupin producer, growing around $85 \%$ of the global crop $(11,25)$. The southwestern Australian grainbelt is responsible for $80 \%$ of Australia's production, 95\% of this being Lupinus angustifolius (narrow-leafed lupin; 10). L. angustifolius is also an important component of Australian crop rotations because it helps in the management of fungal root diseases of cereals, soil rehabilitation, and, due to its nitrogen-fixing capabilities, improving the yield of cereal crops grown in rotation with it $(3,13)$.

Southwestern Australia has a Mediterranean-type climate with predominantly sandy soils suitable for $L$. angustifolius crops $(2,11)$. Although yields are commonly 1 to $2 \mathrm{t} / \mathrm{ha}$, the potential exists for $4 \mathrm{t} / \mathrm{ha}$. Currently, one of the major reasons for poor yields is black pod syndrome (BPS), which was first noticed in the 1990s (12). L. angustifolius plants affected by BPS are seen late in the growing season, after first flowering, when they develop characteristic flat, black pods that have little or no seed. Damage to crops can be extensive, with losses of $40 \%$ reported (2). Possible causes of BPS that were hypothesized included (i) excessive vegetative growth leading to poor pod set, (ii) nutrient deficiencies, and (iii)

Corresponding author: M. A. Kehoe,

E-mail: monica.kehoe@agric.wa.gov.au

This study forms part of a Ph.D. project by M. A. Kehoe at University of Western Australia.

Accepted for publication 12 January 2014.

http://dx.doi.org/10.1094/PDIS-11-13-1144-RE

(C) 2014 The American Phytopathological Society infection with Bean yellow mosaic virus (BYMV) (family Potyviridae, genus Potyvirus). The excessive vegetative growth leading to poor pod set hypothesis was not supported in field experiments consisting of treatments with or without growth hormone applied to different L. angustifolius genotypes (32). Also, nutrient deficiency was disproved when full rates of fertilizer application had no effect on the levels of BPS in different $L$. angustifolius genotypes. BYMV is nonpersistently transmitted by aphids $(16,21)$. Consequently, when two insecticides were applied every 2 weeks at double the recommended rates, levels of BPS were diminished, providing some support for the suggestion that BYMV vectored by aphids may be playing a role (31). However, BPS symptoms were sometimes present in the primary pods without any of the necrotic stem streaking symptoms usually associated with BYMV infection in L. angustifolius, and enzyme-linked immunosorbent assay (ELISA) tests failed to detect BYMV from the majority of BPSsymptomatic plant samples tested (R. A. C. Jones, unpublished).

In 1996 to 2003, L. angustifolius crop variety trials (CVTs) were rated for BPS at the end of the growing season, and BYMV was considered the most likely cause (12,31). However, annual field resistance screening experiments involving young L. angustifolius plants found no difference in susceptibility between BYMV-susceptible breeding lines and lines identified in CVTs as being partially resistant to BPS (18). Thus, rating young plants for BYMV resistance in the field gave different results from rating mature plants for BPS at the end of the growing season (after pod formation). CVTs in 2005 demonstrated a correlation between high levels of BPS and diminished grain yields, and a genetic basis to partial BPS resistance was suggested. Subsequently, a cultivar with partial BPS resistance was released under the name 'Jenabillup' $(2,32)$.

Single dominant hypersensitivity gene $\mathrm{Nbm}-1$ confers systemic hypersensitive resistance to BYMV in L. angustifolius (22). A small proportion of BYMV isolates found in the field overcome this resistance $(4,5)$. When other BYMV isolates infect $L$. angustifolius plants early in the growing period, their interaction with Nbm-1 causes young plants to die from systemic necrosis. This 
removes the infected plant from the crop, so that it no longer acts as a source of infection for further within-crop virus spread $(4,5,19)$. The most common BYMV source for virus spread to $L$. angustifolius crops in southwestern Australia is nearby infected legume pastures dominated by Trifolium subterraneum (subterranean clover). BYMV is seedborne in T. subterraneum and other annual pasture clover species and survives the hot dry summer conditions inside dormant seed in the soil seed bank $(15,16,27)$. However, BYMV is not seedborne in L. angustifolius $(16,21)$. Other sources include neighboring infected L. angustifolius crops, other grain legume crops, and native legumes $(16,24,26)$. Except for one isolate from a metropolitan plant breeding site, all BYMV isolates from southwestern Australia that have been sequenced are in the "general" phylogenetic grouping of BYMV (33).

Improvements to domesticated $L$. angustifolius cultivars include breeding for disease resistance (8). For viruses, breeding has focused on reducing levels of seed transmission of Cucumber mosaic virus (CMV) (family Bromoviridae, genus Cucumovirus; 16,20). Although the $N b m-1$ gene is present in all cultivars of L. angustifolius evaluated thus far, this is not the consequence of active plant breeding $(4,5,18,22)$. Finding the genetic basis of partial resistance to BPS is of great interest to L. angustifolius breeding programs (12). This article describes research to establish the cause of BPS in $L$. angustifolius by testing the hypothesis that BPS is caused by late infection with BYMV. It also describes research to identify the most reliable approach for detecting BYMV within BPS-symptomatic plants, and where BYMV isolated from BPS-symptomatic plants fit within its phylogenetic groupings.

\section{Materials and Methods}

Glasshouse grown plants, inoculations, and virus isolate cultures. All plants were maintained at 18 to $22^{\circ} \mathrm{C}$ in an insect-proof glasshouse. Plants of L. angustifolius were grown in washed river sand and plants of Nicotiana benthamiana and T. subterraneum 'Woogenellup' in steam-sterilized potting mix. For mechanical inoculations to maintain cultures or as part of experiments, virusinfected leaves from recently systemically infected plants were

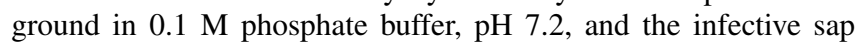
was mixed with celite before being rubbed onto leaves. Cultures of virus isolates were maintained by serial mechanical inoculation of infective sap to plants of $N$. benthamaniana or T. subterraneum. Isolate BYMV-MI was obtained from freeze-dried leaf material from previous research (14) and had previously been shown to be part of the general phylogenetic grouping for BYMV (33). New BYMV isolate AR93C was obtained in 2011 from a plant with BPS at Arthur River, southwestern Australia. Leaf samples from $T$. subterraneum plants infected with BYMV were used as the positive control in ELISA and reverse-transcription polymerase chain reaction (RT-PCR), and as inoculum for the experiments. An isolate of Clover yellow vein virus (ClYVV) (family Potyviridae, genus Potyvirus) from New South Wales, Australia, was from freeze-dried leaf material obtained from the West Australian Plant Pathogen Culture Collection (WAC10102). It was mechanically inoculated to plants of $T$. subterraneum and maintained in this species, as with the BYMV cultures, and used as a positive control for ELISA and RT-PCR testing.

ELISA. For testing by ELISA, samples were extracted $(1 \mathrm{~g}$ per $20 \mathrm{ml})$ in phosphate-buffered saline $(10 \mathrm{mM}$ potassium phosphate, $150 \mathrm{mM}$ sodium chloride [pH 7.4], Tween 20 at $5 \mathrm{ml} /$ liter, and polyvinyl pyrrolidone at $20 \mathrm{~g} /$ liter) using a mixer mill (Retsch). Sample extracts were tested for BYMV or CIYVV by double-antibody sandwich ELISA, as described by Clark and Adams (6). For generic potyvirus testing, samples were extracted in $0.05 \mathrm{M}$ sodium carbonate buffer, $\mathrm{pH} 9.6$, and tested using the antigen-coated indirect ELISA protocol of Torrance and Pead (29). The polyclonal antiserum to BYMV was from DSMZ, to ClYVV from Adgen, and to generic potyvirus from Agdia. All samples were tested in duplicate wells in microtiter plates. Sap from BYMV- or CIYVVinfected and healthy T. subterraneum leaf samples was included in paired wells to provide positive and negative controls. The sub- strate was $p$-nitrophenyl phosphate at $1.0 \mathrm{mg} / \mathrm{ml}$ in diethanolamine, $\mathrm{pH} 9.8$, at $100 \mathrm{ml} / \mathrm{liter}$. Values for absorbance at $405 \mathrm{~nm}$ were measured in a microplate reader (Bio-Rad Laboratories). Absorbance values of positive samples were always more than three times those of the healthy sap control.

RT-PCR and sequencing. For testing by RT-PCR, total RNA was extracted from each sample using a Spectrum Plant Total RNA kit (Sigma-Aldrich), according to the manufacturer's instructions. Reverse transcription was performed using Improm-II reverse transcriptase (Promega), according to the manufacturer's instructions, using the random primers provided. PCR was performed with the GoTaq green master mix (Promega), according to the manufacturer's instructions. Primers used for BYMV were LegPotyF and BYMVUTR-rev from Wylie et al. (33), generic potyvirus identification primers LegPotyF and LegPotyR from Webster (30), and CIYVV primers CIYVV-F and ClYVV-R from Larsen et al. (23). The PCR products of eight samples from BPS-symptomatic plants were sequenced using an Applied Biosystems 3730 DNA analyzer with Big Dye Terminator 3.1 chemistry. Sequence trimming and analysis was done using Geneious Pro 5.6.2. Partial coat protein (CP) sequences were submitted to GenBank with the accession numbers KF823008 to KF823015. In addition to the 8 new partial CPs, 15 other CP sequences selected to represent each of the seven different phylogenetic groups of BYMV, were retrieved from GenBank (33). Sequences were all trimmed to 431 nucleotides (Geneious Pro 5.6.2.), alignments were performed with Clustal W, and neighbor-joining phylogenetic trees with a bootstrap value of 1,000 were constructed using MEGA 5.0 (28).

Survey for BPS and comparison of virus testing methods. A late-growing-season survey to obtain samples of BPS-symptomatic L. angustifolius plants was conducted in southwestern Australia in September and October 2011. Survey locations were six farms: three at Gibson and one each at Arthur River, Pingelly, and Wongan Hills (Fig. 1). Samples were from (i) crops of 'Jenabillup' at two farms at Gibson and (ii) L. angustifolius CVTs or experimental plots for screening L. angustifolius accessions for various traits at the remaining farms. No BPS-symptomatic plants were found at Wongan Hills. In total, 72 symptomatic whole plants were collected from the other five locations. To assess the most appropriate sampling position for reliable detection of BYMV in these samples, two to five positions on the shoots of each symptomatic whole plant were sampled. Every plant was sampled in the middle of the main stem (typically still green but with necrotic streaking) and at the top of the main stem near the primary black pods. Only 48 of the symptomatic plants had not yet shed their youngest leaves and these were tested when still present. Seven plants from Gibson with BPS but with minimal or no stem streaking still had their older leaves present and these, along with their petioles, were sampled. In total, 206 samples from the 72 symptomatic plants were tested by ELISA and RT-PCR for generic potyvirus, BYMV, and CIYVV.

Induction of BPS by BYMV inoculation. An initial glasshouse experiment was conducted to determine (i) whether late BYMV infection could induce BPS in plants of L. angustifolius 'Mandelup' (BPS susceptible) and (ii) whether BYMV from a source other than BPS-symptomatic L. angustifolius plants could induce BPS. Five plants were mechanically inoculated with BYMV-MI at first flowering (i.e., flowering on the main stem) and another five plants 2 weeks later, as primary pods were forming on the main stem. Five plants were left uninoculated as healthy controls. Once symptoms had formed, young leaf samples from each plant were tested individually by ELISA for BYMV.

Effect of plant growth stage at time of infection. A further glasshouse experiment was done with L. angustifolius 'Mandelup' (BPS susceptible) and Jenabillup (partially BPS resistant) to assess the importance of growth stage at the time of inoculation with a BYMV isolate from a BPS-symptomatic plant. Growth stage at the time of inoculation was determined based on the descriptions given by Dracup and Kirby (9). Eight plants were mechanically inoculated with BYMV isolate AR93C at 2-week intervals beginning at 
6 weeks after sowing. At the time of inoculation, the first growth stage had only leaflets present. The subsequent growth stages at each 2-week interval consisted of stem elongation; bud formation; buds and initial flowers; first flowering and primary pods; full primary pods and secondary flowers; full primary and secondary pods, with tertiary flowers; and the inoculations finished after 20 weeks, with the final growth stage, where pods were forming on tertiary shoots but pods on the primary and secondary shoots were fully formed (9). At each stage and for each cultivar, eight plants were mock inoculated with healthy leaf sap from a T. subterraneum plant to act as controls. Young leaf samples were taken from plants inoculated at growth stages 1 to 5 and tested individually by ELISA for BYMV and generic potyvirus. Stem material from just below the black pods on the main stem was sampled from plants inoculated at growth stages 6 to 8 and tested individually by RTPCR for BYMV and generic potyvirus. Testing occurred once symptoms appeared, with this being 2 to 3 weeks after inoculation for stages 1 to 5 , where the symptoms presented as typical early BYMV infection on both the leaf and stem, and 4 to 6 weeks after inoculation for stages 6 to 8 , where the symptoms presented as black pod symptoms.

\section{Results}

Survey for BPS, ELISA, and RT-PCR testing and isolate sequencing. Regardless of sampling location on BPS-symptomatic plants, the greatest numbers of virus detections were achieved using generic potyvirus primers by RT-PCR (Table 1). In particular, the main stem just below the black pods was the most reliable sampling location, giving a positive result with 71 of 72 samples. When the same samples were tested by RT-PCR using BYMVspecific primers, 59 of 72 gave positive results, including the single sample that was not detected with generic potyvirus primers. ELISA testing of the same samples was less reliable, giving positive results for 54 of 72 samples with generic potyvirus antibodies and 60 of 72 samples with BYMV-specific antibodies. The remaining sampling locations were not as reliable or suitable for testing because detections varied greatly, depending on whether generic potyvirus antibodies for ELISA, BYMV-specific antibodies for ELISA, generic potyvirus primers for RT-PCR, or specific BYMV primers for RT-PCR were used. When the midstem samples were tested, positive detections were 24 to 44 of 72 for ELISA and 42 to 64 of 72 for RT-PCR. When testing younger leaves in plants in which they had not yet been shed, positive detections were 1 to 9 of 48 for ELISA and 23 to 46 of 48 for RT-PCR. Testing of young leaf petioles gave positive detections in 0 to 1 of 7 for ELISA and 2 to 5 of 7 for RT-PCR. With older leaves, there were no detections by ELISA and 1 to 7 of 7 by RT-PCR. CIYVV was never detected by ELISA or RT-PCR in any of the samples tested.
Direct nucleotide sequencing was performed on RT-PCR products from six samples that gave a positive result by RT-PCR with generic potyvirus primers only and two others which gave positive results with both generic potyvirus primers and BYMV-specific primers. When the eight new partial CP sequences were compared with partial sequences of 15 isolates from GenBank, a neighborjoining 1,000 bootstrap phylogenetic tree placed all eight into the BYMV general group (Fig. 2).

Induction of BPS by BYMV inoculation. In the initial experiment, L. angustifolius 'Mandelup' plants inoculated with BYMVMI at first flowering produced symptoms of bending of the shoot

Table 1. Detection of Bean yellow mosaic virus (BYMV) and Potyvirus in samples from five locations on Lupinus angustifolius plants with black pod syndrome (BPS) using different testing methods ${ }^{\mathrm{a}}$

\begin{tabular}{|c|c|c|c|}
\hline $\begin{array}{l}\text { Sample location on plant, } \\
\text { format }\end{array}$ & $\begin{array}{l}\text { Virus } \\
\text { target }\end{array}$ & $\begin{array}{l}\text { Detected/total } \\
(n)^{b}\end{array}$ & $\begin{array}{l}\text { Detection } \\
(\%)\end{array}$ \\
\hline \multicolumn{4}{|l|}{ Stem just below black pods } \\
\hline \multirow[t]{2}{*}{ ELISA } & Potyvirus & $54 / 72$ & 75 \\
\hline & BYMV & $60 / 72$ & 83 \\
\hline \multirow[t]{2}{*}{ RT-PCR } & Potyvirus & $71 / 72$ & 99 \\
\hline & BYMV & $59 / 72$ & 82 \\
\hline \multicolumn{4}{|l|}{ Midstem } \\
\hline \multirow[t]{2}{*}{ ELISA } & Potyvirus & $24 / 72$ & 33 \\
\hline & BYMV & $44 / 72$ & 61 \\
\hline \multirow[t]{2}{*}{ RT-PCR } & Potyvirus & $64 / 72$ & 89 \\
\hline & BYMV & $42 / 72$ & 58 \\
\hline \multicolumn{4}{|l|}{ Young leaf } \\
\hline \multirow[t]{2}{*}{ ELISA } & Potyvirus & $1 / 48$ & 2 \\
\hline & BYMV & $9 / 48$ & 19 \\
\hline \multirow[t]{2}{*}{ RT-PCR } & Potyvirus & $46 / 48$ & 96 \\
\hline & BYMV & $23 / 48$ & 48 \\
\hline \multicolumn{4}{|l|}{ Young leaf petiole } \\
\hline \multirow[t]{2}{*}{ ELISA } & Potyvirus & $0 / 7$ & - \\
\hline & BYMV & $1 / 7$ & - \\
\hline \multirow[t]{2}{*}{ RT-PCR } & Potyvirus & $5 / 7$ & - \\
\hline & BYMV & $2 / 7$ & - \\
\hline \multicolumn{4}{|l|}{ Old leaf } \\
\hline \multirow[t]{2}{*}{ ELISA } & Potyvirus & $0 / 7$ & - \\
\hline & BYMV & $0 / 7$ & - \\
\hline \multirow[t]{2}{*}{ RT-PCR } & Potyvirus & $7 / 7$ & - \\
\hline & BYMV & $1 / 7$ & - \\
\hline
\end{tabular}

a In total, 72 BPS-symptomatic L. angustifolius plants were collected from five farms in southwestern Australia and each plant was tested individually at two to five sample locations on the plant. Testing was by enzyme-linked immunosorbent assay (ELISA) with BYMV-specific and generic potyvirus antibodies and by reverse-transcription polymerase chain reaction (RT-PCR) with BYMV-specific and generic potyvirus primers.

${ }^{b}$ Number of samples with BYMV detected per number of samples tested.
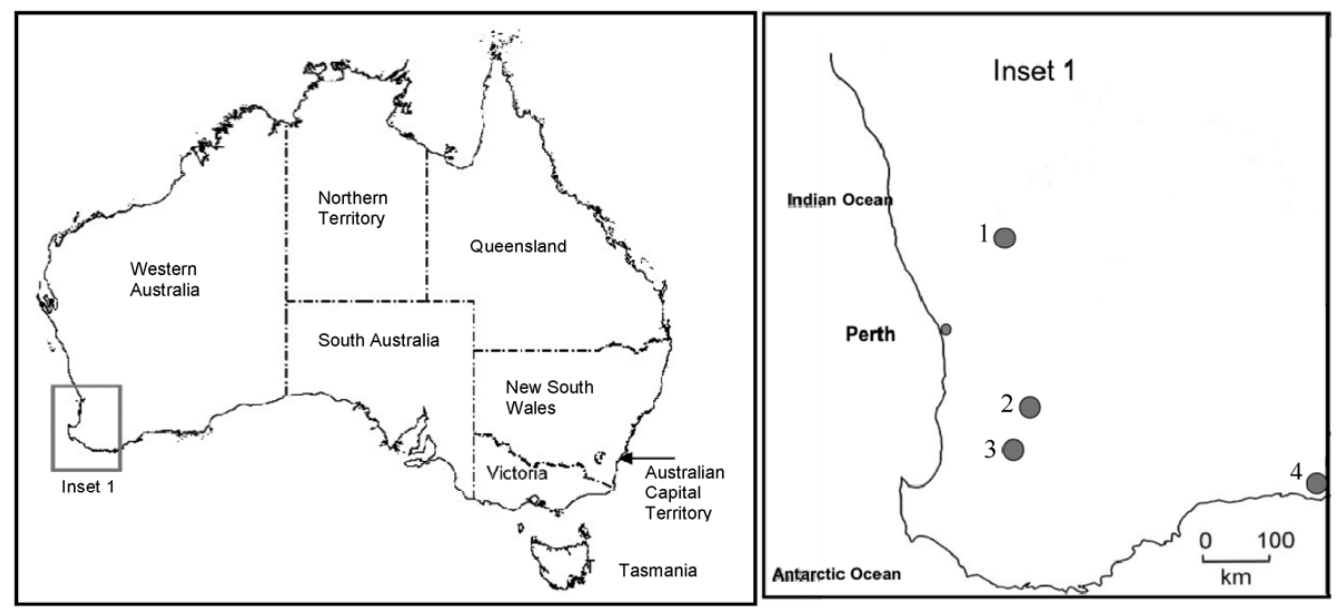

Fig. 1. Locations where black pod syndrome (BPS) symptomatic Lupinus angustifolius plants were collected in Western Australia: map of the Australian continent with an inset for southwestern Australia. Numbered dots represent locations where samples were taken: 1, Wongan Hills; 2, Pingelly; 3, Arthur River; 4, Gibson. 
apex (i.e., a "shepherds crook" appearance), leaf death, severe stem streaking, and necrosis of the stem and growing tips. All five plants inoculated were dead 2 weeks after inoculation. In contrast, four of five plants inoculated when their primary pods had formed developed blackening of their primary pods (i.e., typical BPS symptoms) and necrotic stem streaking (Fig. 3). The remaining plant developed very small pods on the main stem (because the pods were just forming rather than fully formed at the time of inoculation), and these became necrotic and aborted. BPS appeared within 4 weeks of inoculation. Leaf samples taken from all inoculated plants tested positive to BYMV by ELISA. The five uninoculated plants developed no symptoms and no BYMV was detected by ELISA.

Effect of growth stage at time of BYMV inoculation. Depending on growth stage at the time of inoculation with BYMVAR93C, two to eight of eight plants for L. angustifolius 'Jenabillup' and four to eight of eight plants of 'Mandelup' became infected (Table 2). With both cultivars, the first five growth stages were all inoculated before pods were present on the main stem. All infected plants developed BYMV symptoms as described for inoculations at first flowering in the initial experiment. At growth stage 5 (first flowering), any pods that developed after inoculation became necrotic and never formed properly. All infected plants from inoculations at growth stages 1 to 5 died. Inoculation at growth stages 6 to 8 produced symptoms of BPS, including black pods and necrotic stem streaking. It took longer for systemic systems to appear in these plants than at growth stages 1 to 5, and they were not always killed by the infection (Fig. 4). Although BPS symptoms were the same for plants of 'Mandelup' and 'Jenabillup', they appeared sooner after inoculation in 'Mandelup' than in 'Jenabillup'.

\section{Discussion}

This study shows that late infection with BYMV causes BPS in L. angustifolius plants. The survey results satisfy the first condition of Koch's postulates by confirming that "the pathogen is regularly associated with the disease". The second condition states that "the pathogen should be isolated from diseased plants and grown in culture". This was accomplished successfully by culturing isolates in $T$. subterraneum plants. The combined results of the initial glasshouse experiment and the experiment investigating the effect of growth stage at the time of inoculation satisfy the third condition, "that the disease should be reproduced when a culture of the pathogen is used to introduce disease to a healthy susceptible host". Late inoculation with BYMV-MI, which was first isolated from a non-L. angustifolius source (Melilotus indicus), or BYMV-

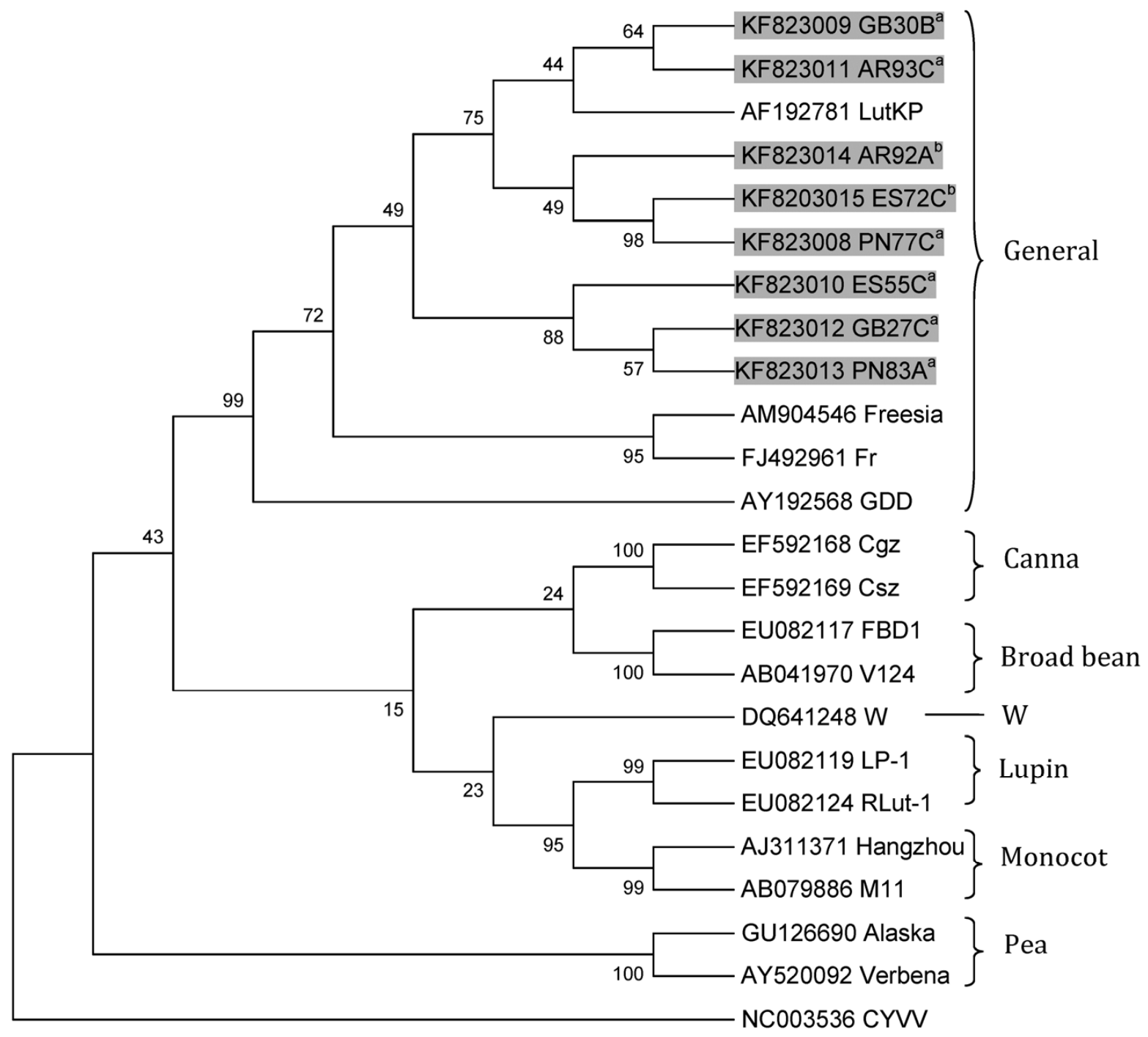

Fig. 2. Neighbor-joining relationship phylogram obtained from the alignment of eight partial coat protein sequences (431 bp in length) belonging to eight Bean yellow mosaic virus (BYMV) isolates collected from black pod syndrome (BPS)-symptomatic Lupinus angustifolius plants in southwestern Australia in 2011. Isolates from this study are highlighted in gray. The other 15 isolate sequences shown were selected from GenBank to represent the seven different BYMV phylogenetic groups (33). The alignment was generated using ClustalW and tree branches were bootstrapped with 1,000 replications. The tree was rooted with Clover yellow vein virus (CIYVV) accession number NC003536. Superscript "a" denotes isolates that were amplified using generic potyvirus primers only and superscript "b" denotes isolates that were amplified using both generic potyvirus primers and specific BYMV primers. 
AR93C isolated from a L. angustifolius plant with BPS, both induced BPS in healthy L. angustifolius plants when inoculated after pods had formed. Finally, in all cases where BPS was induced by BYMV inoculation, the presence of BYMV was confirmed in $L$. angustifolius plants by ELISA or RT-PCR, thus satisfying the fourth condition, that "the pathogen should be detected in or reisolated from the inoculated plants".

From the 72 BPS-symptomatic L. angustifolius survey samples, 12 were positive only using RT-PCR with generic potyvirus primers. Five of these isolates were sequenced and confirmed to be BYMV only. These represent four of the five locations where plants were sampled. Although not sequenced, it seems reasonable to assume here that the remaining seven isolates were also BYMV and that it was the only Potyvirus sp. present. Three other isolates from samples that gave positive detections using both BYMV and generic potyvirus primers were also sequenced and confirmed to be BYMV only. The single sample which gave a positive result with BYMV-specific primers but not with generic potyviruses was a sample of midstem material. It was not chosen for sequencing because the sample taken from just below the black pods on the same plant returned a positive result with both generic potyvirus and specific BYMV primers. We found no evidence of the related Potyvirus ClYVV or any other virus occurring in conjunction with BPS-symptomatic plants in the crops and CVTs surveyed here. However, the possibility that other Potyvirus species might also induce BPS occasionally cannot be discounted (e.g., when ClYVV spreads from T. repens [white clover] pastures to L. angustifolius in other parts of Australia; 17,21). The method used here involving carefully timed mechanical inoculation to $L$. angustifolius plants when the primary pods have fully formed could be used to establish whether BYMV from other phylogenetic groupings (and those from the general group which overcome the Nbm-1 gene) or other viruses, such as ClYVV, can cause BPS. It will also be useful for routine virus resistance screening aimed at advancing the quest for better BPS-resistant L. angustifolius cultivars over the longer term.

The standard method of BYMV identification used worldwide by many plant diagnostic services is ELISA testing on new leaf material. Historically, L. angustifolius samples with BPS were always presented for pathogen identification as dead or nearly dead, dried-out plant samples. This meant they had insufficient living tissue remaining to extract sufficient sap for ELISA testing. The most reliable method of BYMV detection in mature plants with BPS was RT-PCR using generic potyvirus primers on samples taken from the main stem just below the black pods of a BPSsymptomatic plant. This method produced a positive result in 71 of 72 symptomatic plants tested. Regardless of sampling location, RTPCR with BYMV-specific primers and ELISA with generic potyvirus or BYMV-specific antibodies were always less effective. The results from our comparison of sampling locations in the plant and testing procedures explain why ELISA tests failed to detect BYMV in the majority of BPS samples tested in the past. These test results suggest that the concentration or distribution of BYMV in mature plants displaying BPS symptoms may be uneven. The explanation for poor detection with BYMV-specific primers is likely that the reverse primer was not sufficiently complementary to the sequence at the binding site in the new isolates sequenced in this study. The forward primer is a generic primer and is likely to be of sufficiently broad range to accommodate a range of isolates; however, the reverse primer was designed based on the limited number of BYMV sequences available at the time (33). Better BYMV-specific primers could help to improve identification, and further sequencing of more isolates, preferably full genome sequences, will encourage design of better BYMV primers. In the meantime, we recommend the use of RT-PCR testing on stem material for testing $L$. angustifolius plants with BPS symptoms during routine testing.

BYMV is subdivided into seven distinct phylogenetic groupings. The general group is the most primitive and has the widest host range, including both monocots and dicots, and almost all sequenced BYMV isolates from diverse hosts in southwestern Australia belong to it. The other six BYMV groups evolved during plant domestication in different parts of the world and are specialist groupings adapted to distinct types of cultivated plant hosts; for example, the "lupin" group is adapted to broad-leafed lupin species domesticated in the Mediterranean region, such as L. luteus (yellow lupin) and L. albus (white lupin) (33). Interestingly, all the isolates of BYMV collected from BPS-symptomatic L. angustifolius plants were from the general group and none of the specific groups, such as the lupin group. BYMV isolates from this general group are not known to be seedborne in L. angustifolius, which is not surprising because the plants are killed $(16,21)$. If possible, future research should include one or more isolates from these specialist groupings in similar BYMV-BPS experiments, along with isolates of the general grouping that overcome the $\mathrm{Nbm}-1$ gene. It would also be of interest to compare the complete genomes

Table 2. Symptoms and detection of Bean yellow mosaic virus (BYMV) in plants of two cultivars of Lupinus angustifolius inoculated at eight growth stages ${ }^{\text {a }}$

\begin{tabular}{|c|c|c|c|c|}
\hline Growth stage $^{\text {b }}$ & Control or inoculated & Symptoms ${ }^{\mathrm{c}}$ & Jenabillup $^{\text {d }}$ & Mandelup $^{\mathrm{d}}$ \\
\hline \multirow[t]{2}{*}{ 1. Leaflets } & Control & NS & 0 & 0 \\
\hline & Inoculated & SC, NSST, LD, SN & 7 & 5 \\
\hline \multirow[t]{2}{*}{ 2. Stem elongation } & Control & NS & 0 & 0 \\
\hline & Inoculated & SC, NSST, LD, SN & 5 & 5 \\
\hline \multirow[t]{2}{*}{ 3. Bud formation } & Control & NS & 0 & 0 \\
\hline & Inoculated & M, SC, NSST, LD, SN & 2 & 5 \\
\hline \multirow{2}{*}{ 4. Buds and initial flowers } & Control & NS & 0 & 0 \\
\hline & Inoculated & SC, NSST, BPSN, LD, SN & 7 & 6 \\
\hline \multirow[t]{2}{*}{ 5. First flowering and primary pods } & Control & NS & 0 & 0 \\
\hline & Inoculated & NSST, BPSN, LD SN & 8 & 7 \\
\hline \multirow[t]{2}{*}{ 6. Full primary pods, secondary flowers } & Control & NS & 0 & 0 \\
\hline & Inoculated & NSST, BPS, LD, SN & 5 & 7 \\
\hline \multirow{2}{*}{ 7. Full primary and secondary pods, tertiary flowers } & Control & NS & 0 & 0 \\
\hline & Inoculated & NSST, BPS, LD, SN & 7 & 5 \\
\hline \multirow[t]{2}{*}{ 8. Fully podded primary and secondary, and some tertiary pods } & Control & NS & 0 & 0 \\
\hline & Inoculated & NSST, BPS, LD, SN & 7 & 4 \\
\hline
\end{tabular}

a Eight plants each of 'Jenabillup' and 'Mandelup' were mechanically inoculated at 2-week intervals with BYMV isolate AR93C at eight growth stages, beginning with growth stage 1 at 6 weeks after sowing. New leaf samples from each plant were tested individually by enzyme-linked immunosorbent assay (ELISA) for growth stages 1 to 5. Samples taken from the main stem just below the primary pods were tested by reverse-transcription polymerase chain reaction for growth stages 6 to 8 . Eight control plants of each cultivar were inoculated with healthy sap at each growth stage.

${ }^{b}$ Growth stages based on descriptions given in Dracup and Kirby (9).

${ }^{c}$ Coded symptom descriptions: $\mathrm{SC}=$ shepherds crook, $\mathrm{M}=$ mosaic, $\mathrm{LD}=$ leaf drop, NSST $=$ necrotic stem streaking, $\mathrm{SN}=$ systemic necrosis and plant death, $\mathrm{BPS}=$ black pod syndrome, $\mathrm{BPSN}=$ new pods become necrotic and aborted, and $\mathrm{NS}=$ no symptoms.

${ }^{\mathrm{d}}$ Number of plants out of eight inoculated plants in which BYMV was detected by ELISA testing with BYMV-specific antibodies and generic potyvirus antibodies. 
of such isolates with the complete genomes of BYMV isolates from BPS-symptomatic L. angustifolius plants collected as part of this study.

Although 'Jenabillup' proved less susceptible to BPS than 'Mandelup' in experimental field situations (2), this was not reproduced in the glasshouse studies. However, symptoms developed more rapidly after inoculation in 'Mandelup' plants than in 'Jenabillup' plants inoculated at the same time but the final BPS symptoms and their severity were the same. The differences between the field and the glasshouse findings may be due to the use of mechanical inoculation instead of natural inoculation by aphids. Alternatively, the differences may be due to the presence or absence of various modifier genes influencing $N b m-1 \quad(5,22)$. Another possibility is that greater amounts of aphid-inoculation pressure may be required to infect some cultivars than others, such as occurs with BWYV transmission by aphids to different cultivars of Brassica napus (7). Aphids might also have a feeding preference for 'Mandelup' over
'Jenabillup' but further research involving aphid inoculations would be required to investigate these scenarios.

Late-season infection of $L$. angustifolius plants with BYMV resulting in BPS seems likely to result from an interaction between the L. angustifolius hypersensitive resistance gene $N b m-1$ and BYMV. Thus, differences in expression of necrotic symptoms in young (plant death) versus old (BPS) plants probably result from plant growth stage at time of infection in the presence of $\mathrm{Nbm}-1$. When late infection occurs, not all mature plants display necrotic symptoms on all branches $(16,21)$. Possibly, this could be a consequence of physiological changes occurring in the plant at and after flowering or to mature plant resistance in the presence of $N b m-1$ slowing systemic movement in mature plants (1).

There are already integrated disease management recommendations in place for BYMV in L. angustifolius in Australia, such as using perimeter nonhost barriers, avoiding fields with large perimeter/area ratios, retaining stubble ground cover, promoting early
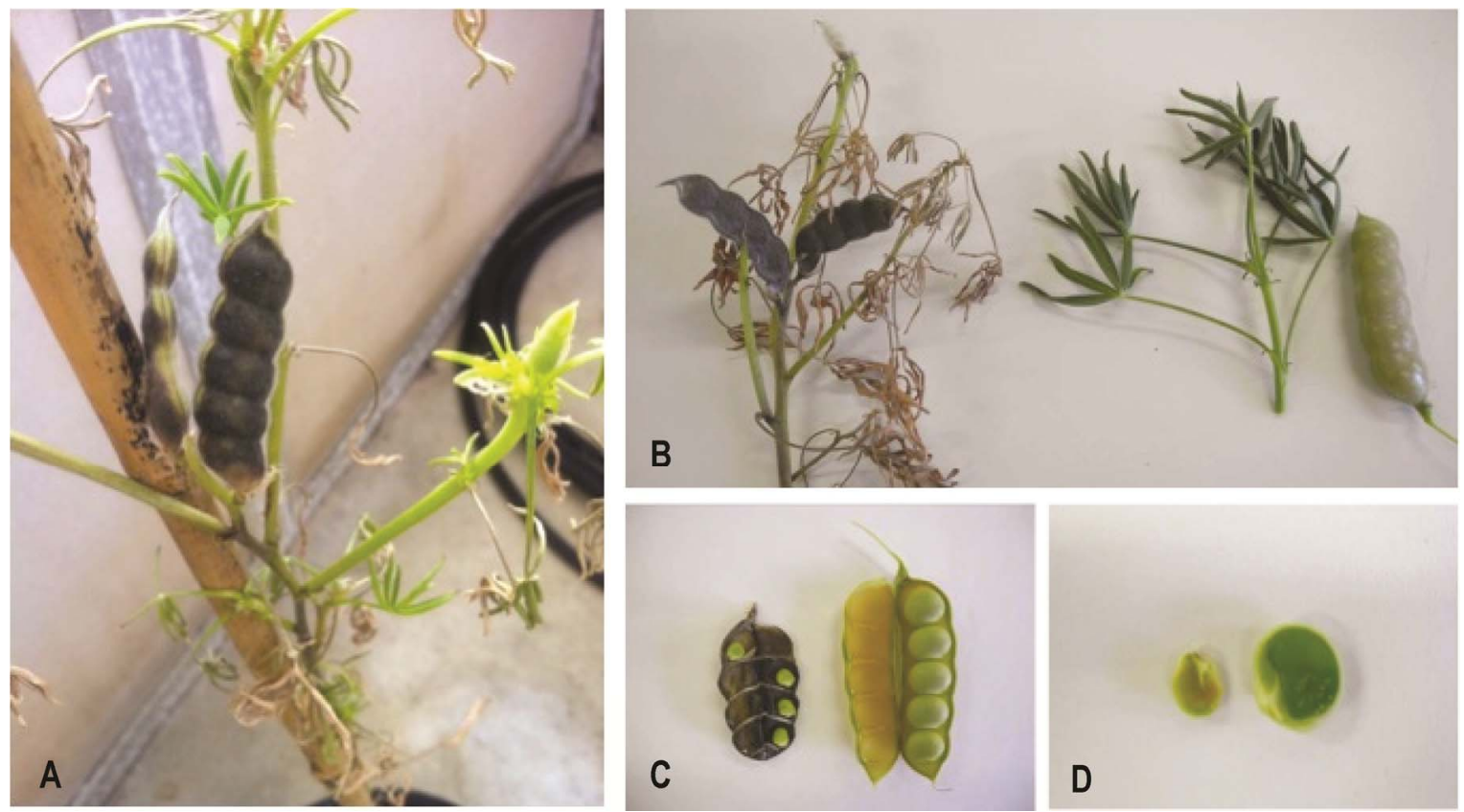

Fig. 3. A, Portion of stem of a Lupinus angustifolius 'Mandelup' plant with black pod syndrome (BPS) in primary pods and necrotic stem streaking following mechanical inoculation with Bean yellow mosaic virus (BYMV) isolate Ml once the primary pods had formed; B, comparison of the apical portions of a $L$. angustifolius 'Mandelup' plant mechanically inoculated with BYMV-MI (left) and an uninoculated control plant (right); C, comparison of opened pods and seed within them produced by the plants shown in B (BPS [left] and healthy [right]); D, comparison of cross sections through seed from the pods shown in C (BPS [left] and healthy [right]).

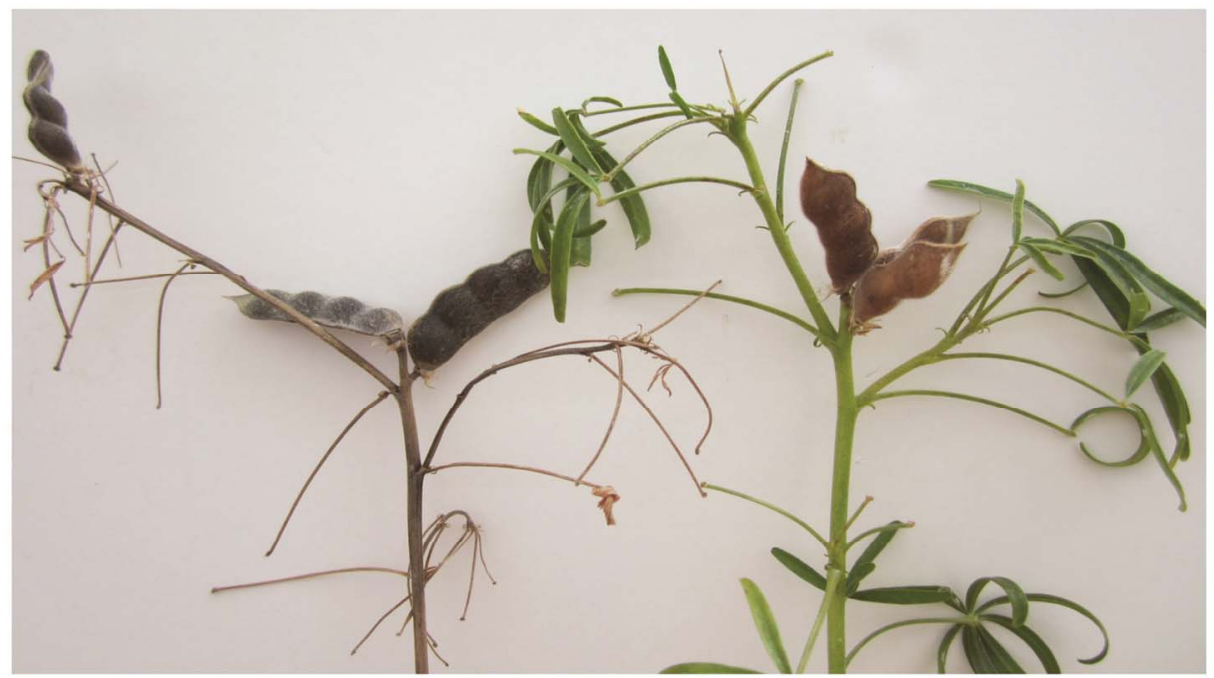

Fig. 4. Apical portion of a Lupinus angustifolius 'Mandelup' plant inoculated with Bean yellow mosaic virus isolate AR93C once primary pods had formed. Note black pods and stem necrosis typical of black pod syndrome (left) compared with healthy (right). 
crop canopy development, generating high plant densities, close row spacing, maximizing weed control, and using crop rotation (16). However, due to the critical importance of growth stage at the time of infection (i.e., podding) for BPS, in this instance, we place particular emphasis on maximizing weed control within the crop (especially clover pasture volunteers) and avoiding planting next to or downwind of legume pastures, other L. angustifolius crops, other grain legume crops, and native legumes that are likely to contain sources of BYMV.

\section{Acknowledgments}

This research was funded by an Australian Postgraduate Award (APA), and an Australian Grains Research and Development Corporation (GRDC) Studentship, Project number GRS10039. It was undertaken using the facilities at the Department of Agriculture and Food Western Australia. We thank P. White for helpful discussions about his earlier studies on BPS; and E. Gajda, S. Vincent, and $\mathrm{M}$. Banovic for glasshouse and laboratory support.

\section{Literature Cited}

1. Beemster, A. P. R. 1987. Virus translocation and mature-plant resistance in potato plants. In: Viruses of Potatoes and Seed Potato Production. J. A. deBokx and J. P. H. van der Meer, eds. Centre for Agricultural Publishing and Documentation, Wageningen, The Netherlands.

2. Buichell, B. J. 2008. Narrow-leafed lupin breeding in Australia-where to from here? Pages 226-230 in: Lupins for Health and Wealth. Proc. 12th Int. Lupin Conf. Fremantle, Western Australia. J. A. Palta and J. B. Berger, eds. International Lupin Association, Canterbury, New Zealand.

3. Chalk, P. M. 1998. Dynamics of biologically fixed $\mathrm{N}$ in legume-cereal rotations: a review. Aust. J. Agric. Res. 49:303-316.

4. Cheng, Y., and Jones, R. A. C. 1999. Distribution and incidence of necrotic and non-necrotic strains of bean yellow mosaic virus in wild and crop lupins. Aust. J. Agric. Res. 50:589-599.

5. Cheng, Y., and Jones, R. A. C. 2000. Biological properties of necrotic and non-necrotic strains of bean yellow mosaic virus in cool season grain legumes. Ann. Appl. Biol. 136:215-227.

6. Clark, M. F., and Adams, A. N. 1977. Characteristics of the microplate method of enzyme-linked immunosorbent assay for the detection of plant viruses. J. Gen. Virol. 34:475-483

7. Coutts, B. A., Webster, C. G., and Jones, R. A. C. 2010. Control of Beet western yellows virus in Brassica napus crops: infection resistance in Australian genotypes and effectiveness of imidacloprid seed dressing. Crop Pasture Sci. 61:321-330.

8. Cowling, W. A., Huyghe, C., and Swiecicki, W. 1998. Lupin breeding. Pages 93-120 in: Lupins as Crop Plants: Biology Production and Utilisation. Gladstones, J. S., Atkins, C., and Hamblin, J., eds. CABI International, Wallingford/New York.

9. Dracup, M., and Kirby, E. J. M. 1996. Lupin Development Guide. University of Western Australia Press, Nedlands, WA, Australia.

10. French, B., Shea, G., and Buirchell, B. 2008. Introduction and history. In: Producing Lupins, Department of Agriculture and Food Western Australia Bulletin 4720, Second Edition. P. White, B. French and A. McLarty, eds. Department of Agriculture and Food, South Perth, WA, Australia.

11. Gladstones, J. S. 1998. Distribution, origin, taxonomy and importance. Pages 1-40 in: Lupins as Crop Plants: Biology Production and Utilisation. J. S. Gladstones, C. Atkins, and J. Hamblin, eds. CABI International, Wallingford/New York.

12. Gladstones, J. S. 1998. Natural resistance to/escape from BYMV in $L$. angustifolius. In: Highlights of Lupin Research and Development in Western Australia: 1998 Crop Updates. G. Shea, ed. Agriculture Western Australia, South Perth, WA, Australia.

13. Harries, M., and Peek, C. 2008. Rotations and farming systems. In: Producing Lupins, Department of Agriculture and Food Western Australia Bulletin 4720, Second Edition. P. White, B. French, and A. McLarty, eds. Department of Agriculture and Food, South Perth, WA, Australia.

14. Jones, R. A. C. 1992. Further studies on losses in productivity caused by infection of annual pasture legumes with three viruses. Aust. J. Agric. Res. 43:1229-1241.

15. Jones, R. A. C. 1993. Effects of cereal borders, admixture with cereals and plant density on the spread of bean yellow mosaic potyvirus into narrowleafed lupins (Lupinus angustifolius). Ann. Appl. Biol. 122:501-518.

16. Jones, R. A. C. 2001. Developing integrated disease management strategies against non-persistently aphid-borne viruses: a model programme. Integr. Pest Manage. Rev. 6:15-46.

17. Jones, R. A. C. 2013. Virus diseases of perennial pasture legumes in Australia: incidences, losses, epidemiology, and management. Crop Pasture Sci. 64:199-215.

18. Jones, R. A. C., and Coutts, B. A. 1998. Screening for resistance to bean yellow mosaic virus in lupins using a disease nursery. In: Highlights of Lupin Research and Development in Western Australia: 1998 Crop Updates. G. Shea, ed. Agriculture Western Australia, South Perth, WA, Australia.

19. Jones, R. A. C., Coutts, B. A., and Cheng, Y. 2003. Yield limiting potential of necrotic and non-necrotic strains of Bean yellow mosaic virus in narrowleafed lupin (Lupinus angustifolius). Aust. J. Agric. Res. 54:849-859.

20. Jones, R. A. C., and Cowling, W. A. 1995. Resistance to seed transmission of cucumber mosaic virus in narrow-leafed lupins (Lupinus angustifolius). Aust. J. Agric. Res. 46:1339-1352.

21. Jones, R. A. C., and McLean, G. D. 1989. Virus diseases of lupins. Ann. Appl. Biol. 114:609-637.

22. Jones, R. A. C., and Smith, L. J. 2005. Inheritance of hypersensitive resistance to Bean yellow mosaic virus in narrow-leafed lupin (Lupinus angustifolius). Ann. Appl. Biol. 146:539-543.

23. Larsen, R. C., Miklas, P. N., Eastwell, K. C., and Grau, C. R. 2008. A strain of Clover yellow vein virus that causes severe pod necrosis disease in snap bean. Plant Dis. 92:1026-1032.

24. Latham, L., and Jones, R. A. C. 2001. Incidence of virus infection in experimental plots, commercial plots and seed stocks of cool season crop legumes. Aust. J. Agric. Res. 52:683-698.

25. Lawrence, L. 2007. Lupins-Australia's role in world markets. In: Australian Commodities, vol. 14, no. 2, June quarter 2007. Australian Bureau of Agricultural and Resource Economics and Sciences, Canberra, ACT, Australia.

26. McKirdy, S. J., Coutts, B. A., and Jones, R.A.C. 1994. Occurrence of bean yellow mosaic virus in subterranean clover pastures and perennial native legumes. Aust. J. Agric. Res. 45:183-194.

27. McKirdy, S. J., Jones, R. A. C., Latham, L. J., and Coutts, B. A. 2000. Bean yellow mosaic potyvirus infection of alternative annual pasture, forage and cool season crop legumes: susceptibility, sensitivity and seed transmission. Aust. J. Agric. Res. 51:325-345.

28. Tamura, K., Peterson, D., Peterson, N., Stecher, G., Nei, M., and Kumar, S. 2011. MEGA5: molecular evolutionary genetics analysis using maximum likelihood, evolutionary distance, and parsimony methods. Mol. Biol. Evol. 28:2731-2739.

29. Torrance, L., and Pead, M. T. 1986. The application of monoclonal antibodies to routine tests for two plant viruses. Pages 103-118 in: Developments in Applied Biology. 1 Developments and Applications on Virus Testing. R.A.C. Jones and L. Torrance, eds. Association of Applied Biologists, Wellesbourne, UK

30. Webster, C. G. 2008. Characterisation of Hardenbergia mosaic virus and development of microarrays for detecting viruses in plants. Ph.D. thesis, Murdoch University, Perth, WA, Australia.

31. White, P., and Baker, M. 2009. Black pod syndrome in lupins can be reduced by regular insecticide sprays. Pages 65-68 in: Proc. Agribusiness Crop Updates: Crop Specific Disease. S. Penny, G. Shea, B. French, A. Douglas, and J. Paterson, eds. Department of Agriculture and Food, South Perth, WA, Australia.

32. White, P., Buirchell, B., and Baker, M. 2007. New lupins adapted to the south coast. Pages 13-17 in: Proc. Agribusiness Crop Updates: Lupin, Pulses and Oilseeds. W. Parker, ed. Department of Agriculture and Food, South Perth, WA, Australia.

33. Wylie, S. J., Coutts, B. A., Jones, M. G. K., and Jones, R. A. C. 2008. Phylogenetic analysis of Bean yellow mosaic virus isolates from four continents: relationship between the seven groups found and their hosts and origins. Plant Dis. 92:1596-1603.

This article was changed on September 18, 2014. In Table 2, a number for Growth stage 6 was changed. 